\title{
Де/ремифологизация образа Шекспира как драматического персонажа в биографической фантазии Дона Нигро «Успешные усилия любви»
}

\author{
Н. А. ВЫСОЦКАЯ
}

(КИЕВСКИЙ НАЦИОНАЛЬНЫЙ ЛИНГВИСТИЧЕСКИЙ УНИВЕРСИТЕТ, УКРАИНА)

Находясь в самом центре западного канона, «Вильям Шекспир» давно превратился в один из его наиболее живучих культурных мифов. На рубеже столетий Шекспир не только как великий художник, но и как активный «инициатор дискурсивных практик» (М. Фуко) - продолжает ощутимо присутствовать в нашей жизни, оказывая мощное воздействие на восприятие западной культурой наиболее фундаментальных категорий бытия. В эпоху постмодернизма распыленный шекспировский «текст», в состав которого входят, среди прочего, его научные и художественные биографии, играет заметную роль как в «высокой», так и в массовой культуре.

В статье исследуются стратегии, используемые американским драматургом Доном Нигро в его «художественной биографии» (Л. Эдель, И. Шаберт) Шекспира - пьесе-фантазии «Успешные усилия любви» (1981/1995), анализируемой в контексте распространенного ныне (под)жанра «автор как персонаж» (П. Франссен, Т. Хонселаарс, А. Фоккема, М. МакКеон и др.). В целом ядром обширной шекспирианы Д. Нигро выступает категория театральности во всем богатстве своих проявлений - от сцены как таковой до человеческой жизни, и далее - до мироздания, где художник/драматург приравнивается к Богу как демиургу.

В статье обоснована мысль о том, что, подвергая деконструкции традиционный миф о Шекспире как о романтическом Поэте, унаследованный от эпохи шекспиромании, Нигро заменяет его собственным мифом о Творце, раздираемом противоречиями между его человеческой и божественной природой.

Ключевые слова: У. Шекспир; образ Шекспира; Дон Нигро; де/ремифологизация; драматический персонаж; биографическая фантазия; «Успешные усилия любви»

\section{ВВЕАЕНИЕ}

$\mathrm{H}$ еизменно сохраняя свое место в сердцевине западного канона, о чем нам не устает напоминать Г. Блум, Уильям Шекспир давно стал одной из его культовых фигур. На рубеже столетий Шекспир - не только как великий художник, но и как активный «инициатор дискурсивных практик» (М. Фуко) - продолжает осуществлять 
воздействие на трактовку основополагающих категорий бытия, по крайней мере, в границах европоцентрического мира. «В этом смысле, обусловив параметры, в которых мы обсуждаем, классифицируем и оцениваем фундаментальные идеи, - отмечает М. Гарбер, - Шекспир сформировал <..> саму возможность социального анализа и культурного диалога наших дней» (Garber, 2008: xxx; здесь и далее перевод наш. - H. B.). С течением времени ценность марки «Шекспир» не девальвируется, однако способы ее эксплуатации меняются в зависимости от нужд и вкусов каждого нового поколения. В культуре постмодернизма рассеянный «шекспировский текст» как сумма всего, написанного им; всего, написанного о нем; его личного мифа; наконец, бесчисленных «кругов по воде», созданных его присутствием в глобальном культурном пространстве на протяжении четырех с половиной веков, составляет неотъемлемую часть этого пространства на всех его ярусах.

Немалая доля шекспировского «текста» приходится на его биографии, как научные, так и художественные. По подсчетам Э. Бартон, «начиная с 1996 г., каждый год выходила в свет минимум одна, а то и несколько крупномасштабных попыток воспроизвести в хронологическом порядке события жизни сына перчаточника из сельского Уорикшира, ставшего величайшим британским поэтом и драматургом; их авторы стремятся вырваться за пределы немногих непреложных и неоднозначных фактов, чтобы обнаружить за ними его личность и убеждения» (Barton, 2006: 22). Речь идет о научных трудах, но поток биографической беллетристики также не иссякает. Анализируя постмодернистские обращения к биографии Шекспира, А. Уильямс утверждает, что «именно присутствие и разработка персонажа Уильяма Шекспира в литературе наших дней способствовали нынешнему увлечению драматургом» (Williams: Электронный ресурс). На наш взгляд, логично говорить о произведениях такого рода в парадигме весьма популярного сегодня (под)жанра «автор как персонаж». Именно в этом ключе рассматривается в данной статье (квази)биографическая пьеса о Шекспире современного американского драматурга А. Нигро. Основной целью при этом представляется исследование драматургических механизмов де- и ремифологизации образа национального гения.

\section{«АВТОР КАК ПЕРСОНАЖ»: НОВЫЙ (ПОА)ЖАНР БИОГРАФИИ}

Нет сомнения в том, что биографическая традиция является одной из древнейших в западной культуре. В то же время биография по-прежнему служит объектом нескончаемых теоретических дебатов в силу своей двойственности как жанрового образования, где факты переплетаются с вымыслом. Не пытаясь даже эскизно наметить очертания данной обширной проблемы, заметим лишь, что в прошлом столетии отчетливо выявилась тенденция к слиянию биографических жанрообразующих конвенций с романными на базе общей для этих жанров стержневой идеи, а именно идеи автономной субъективности. Перенеся центр внимания с внешних событий на внутренний мир персонажа, психобиографии 3. Фрейда и Э. Эриксона, равно как и модернистская «внутренняя биография» (internalized biography) (В. Вулф), оказались предтечами постмодернистских экспериментов с биографическим жанром. В последней четверти XX столетия варианты его переосмысления часто возникали внутри более широкого течения, направленного на пересмотр репрезентации истории в художественной литературе. Этот пересмотр подразумевал, в частности, размывание границ между фактом и вымыслом, присутствующее и в «биографической металитературе» (термин $\Lambda$. Хатчен). Не вступая в прямую конфронтацию с историей (в данном случае с историей индивидуальной жизни), биографы эпохи постмодернизма используют 
стратегии, служащие для ее подрыва изнутри путем произвольной игры с фактами их добавлением и изъятием, перестановкой и (или) неожиданной интерпретацией, с целью продемонстрировать иллюзорность какого бы то ни было позитивного знания о событии или индивидууме. По сути дела, как справедливо отметил Ю. Шлегер, жизнь любого человека как сумма всего пережитого им состоит как из фактов, так и из фантазий, а потому биография, «незаконный отпрыск истории и вымысла» (Schlaeger, 1995: 66), наиболее приспособлена для облачения ее в литературную форму. Акцент ученого на роли воображения и мифотворчества в этом процессе особо существенен в контексте данной статьи.

На сегодняшний день значительный сегмент в биографической литературе образуют биографии писателей, часто выделяемые в отдельный (под)жанр «автор как персонаж». П. Франссен и Т. Хоенселаарс, составители программного сборника «Автор как персонаж: репрезентация писателей в западной литературе» (1999), имеют все основания утверждать, что хотя этот жанр не является недавним изобретением, «сейчас он явно переживает эпоху расцвета» (Franssen, Hoenselaars, 1999: 18). Его популярность может показаться парадоксальной в период, когда Р. Барт, М. Фуко и иже с ними возвестили о «смерти автора». Однако Франссен и Хоенселаарс полагают: «...постмодернизм, провозгласивший “смерть” как автора, так и персонажа, с наслаждением воскрешает исторических авторов и персонажей. Этот прием позволяет в живой и компактной форме не только поставить, но и воплотить такие проблемные узлы постмодернизма, как репрезентация, (не)возможность исторического знания, роль автора в порождении текста, интертекстуальность» (там же: 11).

Ученые полагают, что данный (под)жанр находится «на пересечении исторического романа, биографии и Künstlerroman'а» (там же: 18), реализуясь в разнообразных жанровых формах. Хотя наиболее распространенной из них остается биографический роман, «одной из альтернатив ему оказывается драма <...>, часто используемая Аля изображения писателей прошлого» (там же: 16). М. МакКеон заметил, что «все биографии в определенном смысле являются автобиографиями, особенно в случаях жизнеописаний писателей, где повествуемая история воспроизводится на уровне формы» (McKeon, 1991: 38). Поскольку автор-персонаж, о котором идет речь, ярко проявил себя именно в драме, выбор драматической формы для рассказа о его жизни представляется вполне естественным.

По мнению А. Нейдела, любая биография начинается с легенды, и обязанность биографа состоит в ее исправлении, отрицании и пересмотре. В процессе ревизии фактов биография стремится демифологизировать своего героя, но, по иронии жанра, эта попытка приводит к замене старых мифов новыми (Nadel, 1984: 178). Это суждение справедливо и в нашем случае, особенно если учесть, что А. Нигро ставит в центр своего произведения автора (супра)национального масштаба не только в плане его литературных достижений, но и как мощного агента консолидации нации, интенсивно мифологизированного в коллективной памяти британцев и мирового сообщества.

В своей «художественной биографии» Шекспира (imaginative biography - термин, введенный в обиход $\Lambda$. Эделем) «Успешные усилия любви» (1981/1995) А. Нигро предлагает очередной вариант образа протеистичного английского творца. Шекспировские отзвуки громко звучат во многих произведениях плодовитого американского драматурга - ими пронизана травестия «“Как вам это понравится” Шекспира в постановке сельского священника» (1976/1986), серия монологов «Аевичество шекспировских героинь» (1988/1995), пьеса «Кабанья голова» (2005). Представляется, что 
вся шекспириана Нигро строится вокруг категории театральности в наиболее широком ее понимании - от сценичности per se до образа человеческой жизни и далее мироздания, причем в каждой пьесе она поворачивается новой гранью. Таким образом, театральность используется как универсальная метафора жизни/мира, внедренная в обиход западной культуры еще Платоном и Эпиктетом и пронизывающая всю ее историю. Театральность неразрывно связана с праздничным и игровым началами важными факторами в философии культуры XX в. (Й. Хейзинга, Г.-Г. Гадамер и др.).

A. Нигро воплощает эту идею на практике. В комментариях к пьесе «“Как вам это понравится” Шекспира в постановке сельского священника» он отмечает: «Театр как таковой стал центральной метафорой творчества Шекспира, являясь в определенном отношении и центральной метафорой всей западной цивилизации» (Nigro, 1986: 97). Под пером американского драматурга «театр жизни» приобретает ярко выраженные экзистенциальные черты. Его «малочисленная и бестолковая» труппа, пытающаяся сыграть бессмертную комедию Шекспира, «вглядывается во тьму», не имея не малейшей уверенности, «что там есть некто, наблюдающий за ними» (экзистенциалистский мотив богооставленности). Часто текст пьесы кажется им непонятным, шутки устаревшими. Провал представляется неизбежным. Актеры хотят уйти со сцены, они «уродуют священные слова бога Шекспира, но их настойчивость постепенно приобретает черты своеобразного героизма» (там же: 98). «То, что начиналось как мучения и унижения, превращается в победу <...>. Их положение безнадежно, их ситуация необъяснима, они смехотворны, но борьба придает им определенное достоинство и приносит ощущение кратковременного спасения. Короче говоря, они во всем подобны нам» (там же). Именно в зоне действия метафоры «мир - театр» давняя англо-американская традиция шекспировского бурлеска встречается с поэтикой театра абсурда, вызванного к жизни мрачными реалиями XX в. и покоящегося на философском фундаменте экзистенциализма.

В этом семантическом поле Нигро актуализирует в качестве лейтмотива своих произведений распространенный топос западной культуры - уравнение «Бог $=$ демиург = творец/драматург». М. МакКеон обобщает: «...ренессансная доктрина художника-творца впервые сформулировала дерзкую идею подобия человеческого духа божественному, но лишь Просвещение смогло принять этот вызов, предложив эстетическую теорию, эффективно заменившую божественный авторитет властью автора-человека» (McKeon, 1991: 20). Эта тенденция достигла кульминации в эпоху романтизма, а позднее была подхвачена модернизмом. Отождествление художникатворца с Богом-демиургом проходит красной нитью через все «шекспировские» пьесы Нигро, причем членом этого уравнения порой становится не только Великий Стратфордианец, но и сам автор.

«Успешные усилия любви» представляют собой не только образец (под)жанра «автор как персонаж»; жанровую природу пьесы можно также рассматривать как драматическую фантазию, основанную на фактах биографии Барда. Намеренно архаизированное название апеллирует как к ранней комедии Шекспира «Бесплодные усилия любви» (вторая половина 1590-х гг.), так и к ее «зеркальному двойнику»- пьесе «Успешные усилия любви», написанной, предположительно, в тот же период, но, увы, не сохранившейся для потомства. О ней, впрочем, упоминается в источниках того времени, например в «Сокровищнице ума» (Palladis Tamia. Wits Treasury, 1598) Ф. Mepeза, которому мы обязаны целым рядом драгоценных свидетельств о Шекспире и его произведениях. Нигро, однако, не делает ни малейшей попытки реконструировать ут- 
раченный текст; вместо этого он сплетает узор из символических образов вокруг личности его создателя. Стоит отметить, что, ставя Шекспира в центр драматургического повествования, Нигро мог опираться на опыт выдающихся предшественников, в частности Аж. Б. Шоу ( «Смуглая леди сонетов», 1910) и Э. Бонда ( Бинго», 1973).

В послесловии к пьесе Аон Нигро считает необходимым прояснить свою позицию как биографа-художника. Он полагает, что критики, настаивающие на невозможности написать хорошую пьесу о Шекспире, «не делают различия между мифологизированной и дискурсивной формами» (Nigro, 1995: 102), воплощенными, соответственно, в искусстве и истории. Относя свой эксперимент к первой из этих форм, Нигро характеризует пьесу как «изменчивый узор символов, реконструкцию архетипной модели, порождающей не дискурсивные, а мифологические истины». Поскольку он трактует образ Шекспира как драматург, а не как критик или историк, великий писатель является для него мифологической фигурой, «такой же, какими Ричард III, леди Макбет или Фальстаф были, вероятно, для Шекспира» (там же). Нигро предполагает, что Шекспиру не было важно, насколько нарисованный им портрет Ричарда верен «истине». «Араматург использует исторических персонажей так же, как персонажей свой частной истории, для создания мифов» (там же: 103). В этом вопросе мнение американского автора совпадает с позицией Н. Фрая, для которого биография не может быть ничем иным, кроме мифологии, так как транспонирует индивидуальные усилия в мифологический опыт, двигаясь от метонимии к метафоре, от индивидуальной жизненной борьбы к универсальной ситуации. Таким образом, биография перемещается из области истории в область мифа (Frye, 2006: 43).

\section{НЕАИНЕЙНАЯ АРХИТЕКТОНИКА ПЬЕСЫ А. НИГРО}

Потенциал Шекспира как мифологического героя усиливается грандиозностью его творческого подвига. Именно созидательный порыв связывает его, «если двигаться вверх по вертикали архетипной шкалы, с другим мифологическим героем - Богом Ветхого Завета, а если двигаться вниз - со мной, еще одним творцом и создателем вселенной» (Nigro, 1995: 104-105). Здесь со всей очевидностью реализуются рассмотренные выше формулы «художник = творец» и «драматург = демиург». По сути дела, Нигро намеренно уклоняется от разграничения «поэзии» и «правды», стремясь слить их в единую поэтическую истину.

В соответствии с моделью, ставшей в современных художественных биографиях почти обязательной, Нигро отказывается от соблюдения хронологической последовательности событий. Пьеса с ее нелинейной архитектоникой лишена традиционного сюжета - вместо него предлагается серия разрозненных эпизодов из раздичных периодов жизни Шекспира. Предполагается, что в зрительском восприятии они сложатся в единый «текст», образуя не внешнюю, а внутреннюю (психо)биографию художника. В самом деле, при всей фрагментарности структуры сцены пьесы «цементируются» с помощью разнообразных драматургических и сценических приемов. Среди них - одновременное присутствие на сцене персонажей из разных хронотопов; соположение и столкновение реплик из предыдущего и последующего эпизодов, создающие «мостики» между ними; отсутствие четких пространственно-временных кордонов между сценами, в результате чего возникает эффект непрерывного действия; использование полисемантичных вербальных и театральных метафор. Хотя содержательный пласт пьесы образуют более или менее достоверные факты биографии Шекспира (брак с Энн Хэтәуэй, лондонский круг «университетских разумников», те- 
атральные успехи и провалы, возвращение в Стратфорд и смерть), тем не менее на сцене создано виртуальное, фантасмагорическое пространство. В нем исторические персонажи (королева Елизавета, Кристофер Марло, Роберт Грин, Филип Хенслоу, Ричард Бербедж, Эдвард Аллейн и др.) сосуществуют и взаимодействуют с полулегендарными (Смуглая Меди), а также с литературными героями и другими созданиями шекспировской фантазии. Их идентичности мерцают, нарушая межличностные границы и переходя друг в друга, подобно сновидческим или мифологическим оборотням, - так, например, утонувшая Офелия оказывается Смуглой Аеди. Шекспир у Нигро сам декларирует этот принцип в прологе пьесы: «Я бежал в ужасе и горе от лесов и полей Стратфорда в призрачный город, вот этот, и здесь я жил фантазиями, окутанный театральными вымыслами, пока выдуманное и реальное не перепутались так безнадежно, что я уже не в состоянии разделить их» (там же: 7). Под пером автора, зачарованного театральностью, типичная биографическая дихотомия «факт vs. вымысел» переосмысляется как оппозиция между жизненной реальностью и театральной фантазией. В результате ее стирания действие пьесы разворачивается в онирическом модусе воспоминаний, снов и видений.

Идея универсальной театральности выражена как на драматургическом, так и на сценическом языке насыщенными вербальными и визуальными метафорами и символами. В частности, важные смыслообразующие функции возложены на образ «люка/ямы/ловушки» (trap). В начале пьесы это просто элемент сценической конструкции - люк в полу для появления и ухода со сцены персонажей. По ходу действия он приобретает амбивалентные эротико-танатологические коннотации, обозначая вагину/женщину и могилу/смерть, чтобы в финале стать символом всего физического мира, неизменно стремящегося «поймать» творческую личность в свои ловушки.

Риторические стратегии пьесы определяет сочетание высокой поэтичности и предельного натурализма, граничащего с физиологией. Это и развитая метафорика каннибализма, и шекспировское восприятие Һондона как обители смерти и разложения: «...дохлые животные, навозные кучи, остатки мясных туш, требуха на улицах, ведра крови, которые цирюльники выливают из окон, как грязную воду, нечистая река, нечистые дома, нечистые люди, изуродованные и умирающие, пьяные убийцы, душегубы» (там же: 45). Смысловые и стилевые контрасты характерны для эстетики маньеризма и барокко, творчески усвоенной Шекспиром и имитируемой Нигро. Пьеса также насквозь интертекстуальна; в ее фактуру искусно вкраплены многочисленные явные и скрытые шекспировские цитаты и аллюзии. Неотъемлемым элементом словесной ткани пьесы являются каламбуры, в сочинении которых Нигро проявил немалое мастерство. В качестве примеров можно привести строки из пролога: “Oh, for a muse on fire, Oh, for musing friar» или парафраз знаменитого восклицания Ричарда III, где вместо «коня» (horse) царство предлагается за «катафалк» (hearse) (там же: 85).

Центральный нигровский концепт «мир - театр» дополняется в «Успешных усилиях любви» противостоянием, или, вернее, диалектикой материального и духовного - двух основополагающих начал, увлекающих Шекспира в противоположных направлениях. Их воплощают инфернальные ( «хтонические») и возвышенные ( «воздушные») женские образы - Энн, Смуглая Аеди, дочери поэта Ажудит и Сюзанна, равно как и его героини. Преходящая и временная сущность любой материи, обреченной на смерть и разрушение, противопоставляется бессмертию созданий Ауха. В финале пьесы, выступая от имени всех шекспировских творений, Миранда утешает одинокого, больного и отчаявшегося автора: «Глупенький, у тебя есть МЫ. Ты можешь утратить 
Арузей, любимых, детей, но ты не можешь утратить нас, мы у тебя в голове. Все реальное взято взаймы. Оно прекрасно, но оно не твое. Вся плоть взята взаймы. То, что берешь взаймы, драгоценно, его нужно беречь и ценить, но не путай его с тем, что не взято взаймы. Мы находимся в твоей душе. Мы созданы из материала твоей души» (там же: 99). В ее тираде слышны отзвуки монолога короля $\Lambda$ ира, прозревшего и сдирающего с себя посреди вересковой пустоши больше не нужную одежду, и известных строк Просперо из «Бури». Именно взаимодействие между этими первоначалами определяет, по мнению автора, «алхимию» театра, где продукт воображения драматурга материализуется на сцене, а затем, «во время спектакля, благодаря актерам, вновь переходит в область воображения, но теперь уже зрительского» (там же: 101). «Органический мир создал нас, - заключает Нигро. - А искусство создаем мы. Мы часть обоих миров, нуждаемся в обоих, боимся обоих. Оба мира хрупки. Оба могут обрушиться на тебя в любой момент. Это и есть любовь» (там же: 102).

Итак, традиционный миф о Шекспире как о небожителе, возвышенном Поэте par excellence, унаследованный от эпохи «бардомании», модулируется у Нигро в миф о противоречивом, мятущемся Создателе, раздираемом на части своей одновременно человеческой и божественной природой. В финале Шекспира поглощает «яма/ловушка», как Аон Жуана в опере Моцарта, что намекает на демоническую составляющую его естества. Этот Шекспир, бесспорно, - человек Нового времени, наш современник, утративший целостность и гармонию с собой и миром. Вероятно, никем иным он и не может быть в произведении, написанном сегодня, как бы страстно Аж. Шапиро ни отстаивал противоположное, утверждая, что «реальный» Шекспир «никоим образом не является нашим современником» (Shapiro, 2010: 10).

\section{ЗАКАЮЧЕНИЕ}

В заключение можно констатировать, что, переосмысляя соотношение «факта/вымысла» в пьесе, принадлежащей к (под)жанру «автор как персонаж», современный драматург склоняется к приоритету вымысла в согласии с постулатами постмодернистского мироощущения и поэтики. Избрав героем биографического произведения творческую личность, сыгравшую значительную роль в формировании британской/американской национальной идентичности, Нигро ставил перед собой задачу снять патину времени и поклонения с этой культовой фигуры. Его усилия направлены на изъятие Шекспира из мифологических «сюжетов», в герои которых он был произведен с политическими целями легитимации определенных социальных и символических порядков. Однако, предпринимая попытку очеловечить своего персонажа, Араматург неизбежно помещает его в несколько иной, но столь же мифологический «сюжет», где неоромантическое представление о поэте как демиурге сочетается с необарочной апологией смерти и с постмодернистским отрицанием единой неизменной реальности. Его «Шекспир», весьма далекий от своего хрестоматийного прототипа, отвечает на запросы определенного культурного периода, и можно не сомневаться, что на смену ему придут новые версии неисчерпаемого оригинала, востребованные грядущими историческими эпохами.

\section{СПИСОК АИТЕРАТУРЫ}

Barton, A. (2006) The one and only // The New York Review of Books. May 11. P. 22-24.

Franssen, P., Hoenselaars, T. (1999) Introduction. The author as character: Defining a genre // The author as character: Representing historical writers in Western literature / ed. by P. Franssen, 
T. Hoenselaars. Madison, NJ : Fairleigh Dickinson University Press ; L. : Associated University Presses. 313 p. P. 11-35.

Frye, N. (2006) The great code: The Bible and literature / ed. by A. A. Lee. Toronto : University of Toronto Press. xlix, 380 p. (Series: Collected works of Northrop Frye, vol. 19).

Garber, M. (2008) Shakespeare and modern culture. N. Y. : Pantheon Books. 326 p.

McKeon, M. (1991) Writer as hero: Novelistic prefigurations and the emergence of literary biography // Contesting the subject: Essays in the postmodern theory and practice of biography and biographical criticism / ed. by W. H. Epstein. West Lafayette, IN : Purdue University Press. 251 p. P. 17-41.

Nadel, I. B. (1984) Biography: Fiction, fact and form. L. : MacMillan. 248 p.

Nigro, D. (1986) The curate Shakespeare As You Like It (Being the record of one company's attempt to perform the play by William Shakespeare). N. Y. ; L. : Samuel French. 98 p.

Nigro, D. (1995) Loves labours wonne. N. Y. : Samuel French. 106 p.

Schlaeger, J. (1995) Biography: Cult as culture // The art of literary biography / ed. by J. Batchelor. Oxford : Clarendon Press ; N. Y. : Oxford University Press. 289 p. P. 57-71.

Shapiro, J. (2010) Contested Will: Who wrote Shakespeare? N. Y. : Simon \& Schuster. 339 p.

Williams, A. The portrayal of William Shakespeare in modern fiction: The author-character as a sub-genre of the postmodern [Электронный ресурc] // Academia. URL: https://academia.edu/ 2548185/The_Portrayal_of_William_Shakespeare_in_Modern_Fiction_The_Author-Character_ as_a_Sub-Genre_of_the_Post-Modern (дата обращения: 14.01.2015).

Аата поступления: 12.09.2015 2.

\section{DE/REMYTHOLOGIZING SHAKESPEARE \\ AS A DRAMATIS PERSONA IN DON NIGRO'S BIOGRAPHIC FANTASY \\ "LOVES LABOURS WONNE" \\ N. A. VYSOTSKAYA \\ (KIEV NATIONAL LINGUISTIC UNIVERSITY, UKRAINE)}

Being located at the center of the Western canon, as Harold Bloom reminds us, "William Shakespeare" has long become one of its most viable cultural myths. At the turn of the centuries Shakespeare - not solely as a great artist, but also as an active "initiator of discursive practices", to use Foucault's diction, - still remains a powerful presence exerting strong impact upon the manner in which Western habits of thought theorize the most fundamental categories of being. In postmodern period disseminated Shakespearean 'text', including his scholarly and fictional biographies, plays a visible part in global culture, both in its 'high' and 'low' varieties. The paper explores strategies deployed by the American dramatist Don Nigro in his "imaginative biography" (L. Edel, I. Schabert) of Shakespeare - the fantasy play "Loves Labours Wonne" (1981/1995) examined within the framework of popular biographic subgenre 'the author as character' (P. Franssen, T. Hoenselaars, A. Fokkema, M. McKeon and others). D. Nigro's Shakespeareana in its totality has at its core the category of theatricality in its broadest meaning - from the stage per se to human life and further - to the Universe, equating artist/dramatist to demiurgic God.

It is argued that while the play sets out to deconstruct the traditional myth of Shakespeare as a Poet par excellence inherited from the epoch of Bardolatry, Nigro substitutes in its place his own myth of ambivalent and tortured Creator torn apart, Orpheus-like, between his humanity and divinity.

Keywords: W. Shakespeare; Shakespeare as a character, Don Nigro; de/remythologization; character in drama; imaginative biography; "Loves Labours Wonne"

\section{REFERENCES}

Barton, A. (2006) The one and only. The New York Review of Books, May 11, pp. 22-24.

Franssen, P. and Hoenselaars, T. (1999) Introduction. The author as character: Defining a genre. In: The author as character: Representing historical writers in Western literature/ ed. by P. Franssen 
and T. Hoenselaars. Madison, NJ, Fairleigh Dickinson University Press ; London, Associated University Presses. 313 p. Pp. 11-35.

Frye, N. (2006) The great code: The Bible and literature/ ed. by A. A. Lee. Toronto, University of Toronto Press. xlix, 380 p. (Series: Collected works of Northrop Frye, vol. 19).

Garber, M. (2008) Shakespeare and modern culture. New York, Pantheon Books. 326 p.

McKeon, M. (1991) Writer as hero: Novelistic prefigurations and the emergence of literary biography. In: Contesting the subject: Essays in the postmodern theory and practice of biography and biograpbical criticism / ed. by W. H. Epstein. West Lafayette, IN, Purdue University Press. xi, 251 p. Pp. 17-41.

Nadel, I. B. (1984) Biograpby: Fiction, fact and form. London, MacMillan. 248 p.

Nigro, D. (1986) The curate Shakespeare As You Like It (Being the record of one company's attempt to perform the play by William Shakespeare). New York; London, Samuel French. 98 p.

Nigro, D. (1995) Loves labours wonne. New York, Samuel French. 106 p.

Schlaeger, J. (1995) Biography: Cult as culture. In: The art of literary biography / ed. by J. Batchelor. Oxford, Clarendon Press ; New York, Oxford University Press. 289 p. P. 57-71.

Shapiro, J. (2010) Contested Will: Who wrote Shakespeare? New York, Simon \& Schuster. 339 p.

Williams, A. The portrayal of William Shakespeare in modern fiction: The author-character as a sub-genre of the postmodern. Academia [online] Available at: https://academia.edu/2548185/ The_Portrayal_of_William_Shakespeare_in_Modern_Fiction_The_Author-Character_as_a_SubGenre_of_the_Post-Modern (accessed 14.01.2015).

Submission date: 12.09.2015.

Высоцкая Наталия Александровна - доктор филологических наук, профессор, заведующая кафедрой теории и истории мировой литературы Киевского национального лингвистического университета (Украина). Алрес: 03680, Украина, МСП, г. Киев-150, ул. Велика Василевска, А. 73. Тел.: (38) (044) 279-19-97. Эл. алpec: atkol@i.com.ua

Vysotskaya Natalia Aleksandrovna, Doctor of Philology, Professor and Chair, Department of the Theory and History of World Literature, Kiev National Linguistic University (Ukraine). Postal address: 73 Velika Vasilevska St., 03680 MSP Kiev-150, Ukraine. Tel.: (38) (044) 279-19-97. E-mail: atkol@i.com.ua 